\title{
Hydroxychloroquine baseline retinopathy screening: when to refer patients? A practical approach to optimise resource use
}

\author{
Brandon $\mathrm{Yeo}^{1} \cdot$ Rabie Hamad $^{2} \cdot$ Anindita Paul $^{2} \cdot$ Audrey Low $^{3}$ \\ Received: 19 December 2019 / Revised: 24 January 2020 / Accepted: 24 January 2020 / Published online: 13 February 2020 \\ (c) The Royal College of Ophthalmologists 2020
}

Hydroxychloroquine (HCQ) is widely used in the treatment of rheumatoid arthritis (RA) and connective tissue diseases (CTD) $[1,2]$. A recent report estimated that the prevalence of retinal toxicity in patients on long-term HCQ was 7.5\% [3]. The Royal College of Ophthalmologists (RCOphth) published a new guideline recommending all new patients on HCQ should undergo baseline retinopathy screening, ideally within six months of commencing HCQ but definitely within 12 months [4]. We conducted a quality improvement project in two NHS trusts to identify the number of patients starting HCQ and how to utilise retinopathy screening services optimally.

Two NHS trusts contributed to this project: Salford Royal NHS Foundation Trust (SRFT) and Bolton NHS Foundation Trust (Bolton FT), representing tertiary care and district hospital services respectively. We identified patients commenced on HCQ and followed for 12 months using hospital and pharmacy records. We calculated attrition rates of HCQ use and explored cessation reasons. Mid-2017 population estimates for Salford and Bolton were extracted from the Office of National Statistics [5].

The number of patients commenced on HCQ at SRFT was higher compared to Bolton FT (Table 1). SRFT is a tertiary referral centre for CTD and patients living outside of Salford who commenced HCQ were included; thus raising the incidence of patients commenced on HCQ at SRFT artificially to 63 per 100,000 population compared to 40 per 100,000 in Bolton. A total of 272 patients were

Audrey Low

audrey.low@srft.nhs.uk

1 Faculty of Biology, Medicine and Health, The University of Manchester, Manchester, UK

2 Rheumatology Department, Bolton NHS Foundation Trust, Manchester, UK

3 Rheumatology Department, Salford Royal NHS Foundation Trust, Manchester, UK commenced on HCQ across both calendar years (median age 57 years, female preponderance and RA was the most common diagnosis). Of these, 69 patients $(25 \%)$ had discontinued treatment before completing 6 months of treatment. By 12 months, 90 patients (33\%) had discontinued HCQ. Upper gastrointestinal symptoms and inefficacy were the most common cessation reasons (17/90, $18.9 \%$ each).

Pearce et al applied their estimates to the population of the United Kingdom and calculated that 36,444 patients were commenced on HCQ in 2016 [6]. This is a significant annual burden to local ophthalmology services to comply with RCOphth guidelines, not to mention the estimated 166,673 patients who are already on HCQ [6]. Many ophthalmology departments were aware of the creation of new guidelines for formal ophthalmology-based macular/fundal imaging for HCQ retinopathy screening in 2016/2017. It was perhaps only when the final guidance was in place in early 2018 that practicalities such as the funding/staffing of this new ophthalmology workload were considered at local levels.

Our data provide an estimate of patient numbers starting HCQ treatment per annum per capita district general and tertiary hospital population and are in keeping with the estimates from Pearce et al. This information may help with local commissioning of services. With one in four patients stopping HCQ within 6 months of commencement, we suggest timing baseline retinopathy referrals for those still taking HCQ at 6 months. This model of referral will improve retinopathy screening efficiency and reduce commissioning costs.

\section{Compliance with ethical standards}

Conflict of interest The authors declare that they have no conflict of interest.

Publisher's note Springer Nature remains neutral with regard to jurisdictional claims in published maps and institutional affiliations. 
Table 1 Characteristics of patients prescribed hydroxychloroquine, incidence and attrition rates and drug discontinuation reasons.

\begin{tabular}{|c|c|c|}
\hline & $\begin{array}{l}\text { Salford Royal NHS } \\
\text { foundation trust }\end{array}$ & $\begin{array}{l}\text { Bolton NHS } \\
\text { foundation trust }\end{array}$ \\
\hline Study period & $01 / 01 / 2017$ to $31 / 12 / 2017$ & $01 / 01 / 2016$ to $31 / 12 / 2016$ \\
\hline Mid-2017 local population estimates & 251332 & 284813 \\
\hline Patients started on HCQ in 1 year, $n$ & 158 & 114 \\
\hline $\begin{array}{l}\text { Annual incidence of patients } \\
\text { commenced on HCQ }\end{array}$ & 63 per 100000 population & 40 per 100000 population \\
\hline Median age, years & 55.5 & 59.0 \\
\hline Female gender, $n(\%)$ & $119(75.3)$ & $82(71.9)$ \\
\hline \multicolumn{3}{|l|}{ Rheumatological diagnoses } \\
\hline Rheumatoid Arthritis, $n(\%)$ & $99(62.7)$ & $79(69.3)$ \\
\hline Connective tissue disease, $n(\%)$ & $38(24.0)$ & $18(15.8)$ \\
\hline Other, $n(\%)$ & $21(13.3)$ & $17(17.9)$ \\
\hline $\begin{array}{l}\text { Patients stopped HCQ before completing } \\
6 \text { months, } n(\%)\end{array}$ & $45(28.5)$ & $24(21.1)$ \\
\hline $\begin{array}{l}\text { Patients stopped HCQ before completing } \\
12 \text { months, } n(\%)\end{array}$ & $61(38.6)$ & $29(25.4)$ \\
\hline \multicolumn{3}{|c|}{ Reasons for stopping HCQ among discontinuation group } \\
\hline Upper GI symptoms, $n(\%)$ & $7(11.5)$ & $10(34.5)$ \\
\hline Inefficacy, $n(\%)$ & $14(23.0)$ & $3(10.3)$ \\
\hline Itching/rash, $n(\%)$ & $5(8.2)$ & $3(10.3)$ \\
\hline Eye symptoms, $n(\%)$ & $3(4.9)$ & $1(3.4)$ \\
\hline Other/not known/patient choice, $n(\%)$ & $32(52.5)$ & $12(41.4)$ \\
\hline
\end{tabular}

\section{References}

1. Gordon C, Amissah-Arthur M-B, Gayed M, Brown S, Bruce IN, D'Cruz D, et al. The British Society for Rheumatology guideline for the management of systemic lupus erythematosus in adults: executive summary. Rheumatology. 2018;57:14-8. https://aca demic.oup.com/rheumatology/article/57/1/14/4318864

2. National clinical audit for rheumatoid and early inflammatory arthritis. (2018). https://www.hqip.org.uk/wp-content/uploads/ 2018/02/rheumatoid-and-early-inflammatory-arthritis-2nd-annualreport-2016.pdf

3. Melles RB, Marmor MF. The risk of toxic retinopathy in patients on long-term hydroxychloroquine therapy. JAMA Ophthalmol. 2014;132:1453. https://doi.org/10.1001/jamaophthalmol.2014.3459
4. Hydroxychloroquine and chloroquine retinopathy: recommendations on screening. (2018). https://www.rcophth.ac.uk/wp-content/ uploads/2018/07/Hydroxychloroquine-and-Chloroquine-Retinopa thy-Screening-Guideline-Recommendations.pdf

5. Clinical commissioning group population estimates (National Statistics). Office for National Statistics. (2019). https://www.ons.gov. uk/peoplepopulationandcommunity/populationandmigration/ populationestimates/datasets/clinicalcommissioninggroupmidyea rpopulationestimates

6. Pearce FA, Grainge MJ, King AJ, Lanyon PC. O39 Implementing screening for hydroxychloroquine ocular toxicity: how big is the problem? Epidemiology of hydroxychloroquine prescriptions in the UK Clinical Practice Research Datalink. Rheumatology. 2019. https://doi.org/10.1093/rheumatology/kez105.037/5444578 